\title{
Housing and Communal Services of the City: Functioning, Promising Technologies and Development Practices
}

\author{
N. Shcherbakova, T. Degtyaryova, O. Mysova \\ Don State Technical University, Shakhty, Russia \\ *Corresponding author. Email: Navasherbakova@mail.ru
}

\begin{abstract}
The purpose of the article is to identify promising technologies and practices for the development of the sphere of housing and communal services of the city. For research, the authors applied the method of analysis and synthesis. In the course of the research, the concept of the sphere of housing and communal services was considered, a review of scientific publications on the topic of research was carried out, the experience of the functioning of the sphere of housing and communal services of the city was studied. On the basis of the research carried out, the second developed the production and technological system of the sphere of housing and communal services of the city. The authors developed the scheme of functioning of the sphere of housing and communal services of the city, identified promising technologies and practices for the development of the sphere of housing and communal services to create a comfortable urban environment, economical and efficient use of the city's life support resources.
\end{abstract}

Keywords: Keywords: housing and communal services, city, technology, practice, development, comfortable environment.

\section{INTRODUCTION}

Now there is a reforming of the branch of the housing and communal services. Utilities enterprises are introducing innovations. Therefore, it is relevant to study the problems of the functioning of the housing and communal services sector and consider the prospects for its development to improve the quality of services, service real estate, in particular the multi-apartment housing stock of the city, as its element. The reforms of recent years in this area are aimed at improving the state of the housing and communal services sector, creating a comfortable urban environment.

The concept of the of the housing and communal services sphere is given in the regulatory legal acts of the President of the Russian Federation and the Government of the Russian Federation. The sphere of housing and communal services includes works aimed at ensuring comfortable living conditions for citizens management of apartment buildings, overhaul of common property in apartment buildings; provision of the city with resources (water, gas, electricity, heat), improvement of public areas [1].
The field of the housing and communal services is a topical area of research and the following authors are devoted to this problem: Ben Lyons, Edward O’Dwyer, Nilay Shah [2], Alexandr Zamiralov, Maria Khodorchenko, Denis Nasonov [3], Kolyhaeva Yulia [4], E. L. Nikolaeva, V. S. Kazeykin Artem, V. Sedov [5], Arkadiy Larionov, Yulia Larionova, Ludmila Selivanova [6], A. N. Afanasyeva, A. A. Guseinova [7], Lisa W. Gao, Daniel C.W. Ho [8], A. Synnefa, K. Vasilakopoulou, M. Santamouris [9], Edward O'Dwyer, Indranil Pan, Nilay Shah [10], Julio Cesar Ferro De Guimarães, Eliana Andréa Severo, Fernanda Tasso Salmoria [11], Marta Pappalardo, Gilles Debizet [12], Janaina Macke, João Alberto Rubim Sarate, Suane de Atayde Moschen [13], Daniel A. Vallero, Fraser McLeod, Tom Cherrett [14], Cecilia Tortajada, Francisco González-Gómez, Joost Buurman [15], Thomas Bjørner [16], Xiaoyong Xiao, Chao Xie [17].

Ben Lyons, Edward O'Dwyer и Nilay Shah investigated the functioning of the housing and communal services sector as a model reduction for predictive management of centralized and communal heating systems [2]. 
Alexandr Zamiralov, Maria Khodorchenko, Denis Nasonov investigated housing and communal problems using texts on social networks [3]

The development of promising technologies in the field of the housing and communal services as a factor in improving the quality of life of the population was considered Kolyhaeva Yulia [4].

E.L. Nikolaeva, V.S. Kazeykin Artem и V.Sedov investigated the scientific foundations and investment mechanisms for the introduction of socio-energy efficient technologies for building creation and intelligent lifecycle management [5].

Arkadiy Larionov, Yulia Larionova, Ludmila Selivanova investigated the regional features of energy saving development in the operation of housing and underground of the housing and communal services [6].

A.N. Afanasyeva, A.A. Guseinova zoning of urban environment for development and use of unified management and operation of housing stock is considered [7].

Lisa W. Gao, Daniel C.W. Ho explored the prospects of collective action in the management of an apartment building [8].

A. Synnefa, K. Vasilakopoulou, M. Santamouris systematized existing technologies to minimize the energy consumption of apartment buildings [9].

Edward O'Dwyer, Indranil Pan, Nilay Shah investigated an energy management tool like optimal control, planning, forecasting and coordination services for city energy systems [10].

Julio Cesar Ferro De Guimarães, Eliana Andréa Severo, Fernanda Tasso Salmoria investigated the impact of smart governance factors on quality of life in the context of smart cities [11].

Marta Pappalardo, Gilles Debizet investigated the use of solar energy in apartment buildings [12].

Janaina Macke, João Alberto Rubim Sarate, Suane de Atayde Moschen completed a survey of residents in order to assess smart cities [13].

Daniel A. Vallero, Fraser McLeod, Tom Cherrett considered efficient and environmentally sound methods of collecting municipal solid waste, routing and planning of vehicles using examples from practice from around the world [14].

Cecilia Tortajada, Francisco González-Gómez, Joost Buurman explored measures to save water and promote water-saving technologies in five areas of Spain and found that non-pricing measures had a greater impact on water consumption decisions than pricing measures [15].
Thomas Bjørner considers the emergence and development of a «smart energy city» as an academic, normative and applied concept [16].

Xiaoyong Xiao, Chao Xie explored smart urban planning and governance to address urban development challenges and enhance the viability, level and quality of sustainable urban development [17].

Thornbush Mary, Golubchikov Oleg explored the emergence and development of the «smart energy city» as an academic, normative and applied concept. Examined the evolution of the relationship between city, energy and sustainability [18].

This study examined the functioning of the housing and communal services sector, developed the production and technological system of the housing and communal services sector of the city, considered promising technologies and practices for the development of the housing and communal services sector to create a comfortable urban environment.

\section{MATERIALS AND METHODS}

In the field of housing and communal services, three sectors of activities are distinguished:

supply resources;

management of apartment buildings;

contracting work.

Resource supplying organizations provide water supply to the city, supply heat and hot water to apartment buildings, provide the city with electricity, and provide gas supply. In the field of housing and communal services, management companies work. Organizations engaged in contracting work in the housing and communal services of the city provide services for cleaning the city's effluents, and dispose of municipal solid waste.

In accordance with the Federal Law, the Department for the Coordination of of the housing and communal services. A ctivities, the City Administration, together with the Department of Urban Economy, utility centers, management companies and resource supply organizations, is working to enter data into the state of the housing and communal services information system.

The sphere of housing and communal services is characterized by a complex production and technological system (figure 1).

A scheme for the functioning of the sphere of housing and communal services has been developed (figure 2).

It drives, forces the production and technological system of the housing and communal services sector to function qualified personnel of service enterprises. 
Figure 1. Production and technological system of the housing and communal services of the city.

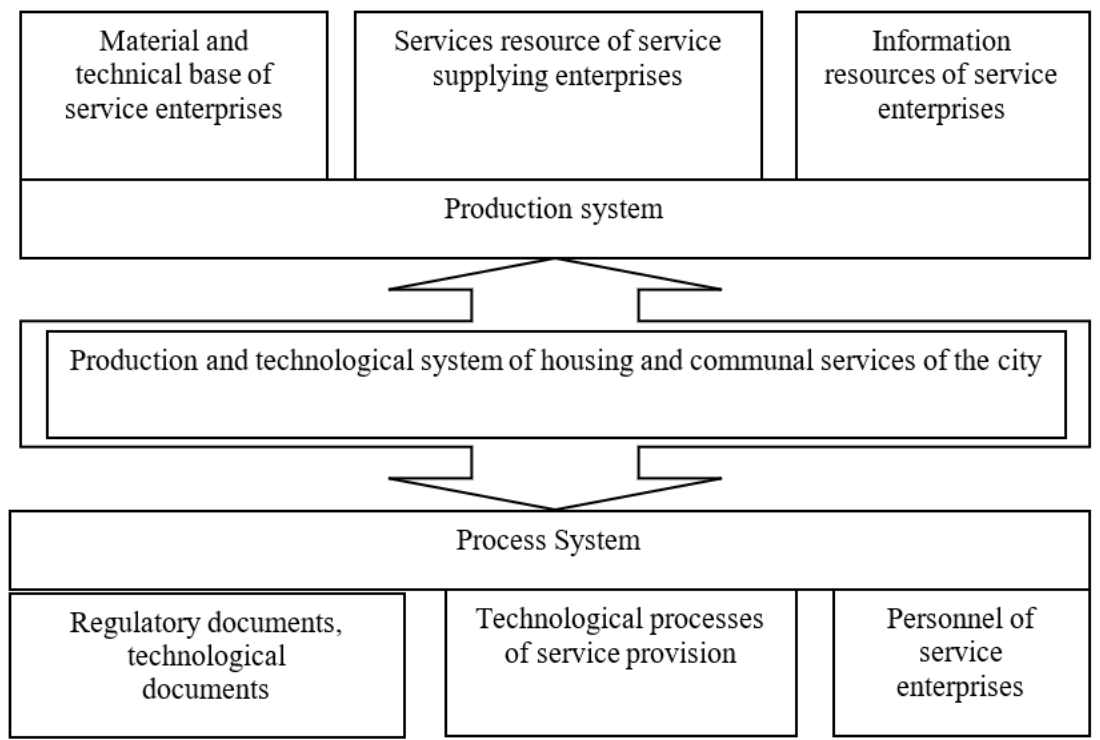

Figure 2. Scheme of the functioning of the sphere of housing and communal services.

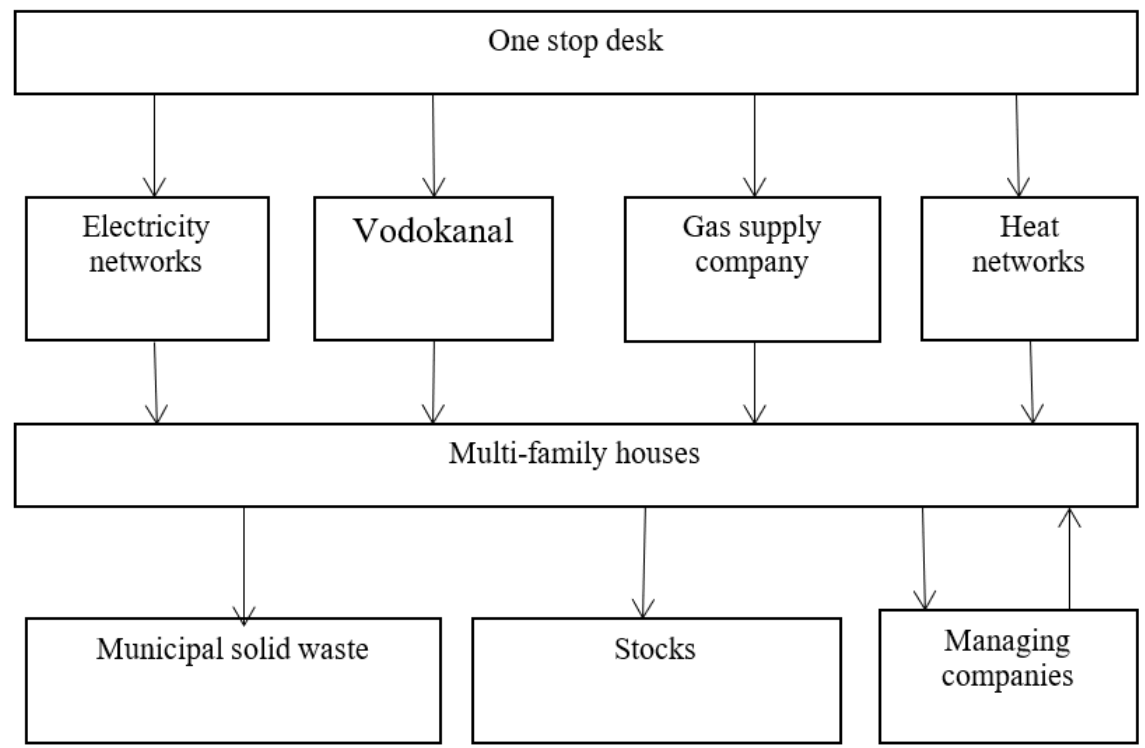

\section{RESULTS}

At the present stage of the transformation of the housing and communal services sector, there are certain trends in the development of the production and technological system - these are promising technologies and practices for creating a comfortable urban environment.

In the field of housing and communal services, the introduction of advanced promising technologies and practices for creating a comfortable urban environment under the Smart City project is being carried out. This project is being implemented in Russia within the framework of the Housing and Urban Environment national project and the Digital Economy national program. The main goal of the Smart City project is to transform the urban economy through the introduction of digital technologies and engineering solutions.

The development of Russian cities is based on five key positions:

1) human orientation;

2) manufacturability of urban infrastructure;

3) improving the quality of urban resource management;

4) comfortable and safe environment;

5) emphasis on economic efficiency, including the service component of the urban environment. 
In the field of housing and communal services, one of the mechanisms for introducing promising technologies and practices to create a comfortable urban environment is the metering system, which allows you to, automatically and simultaneously takes readings from metering devices (individual and common house), makes the process of charging payments for utilities and resources transparent, both for citizens and organizations. The introduction of a dispatching system for metering devices will provide the opportunity to monitor the volume of resource consumption, the state of networks and communal infrastructure in general, as well as quickly respond to possible emergency situations in the city. For resource saving, motion sensors are installed in the entrances of apartment buildings.

In the cities of the country, energy-saving «Smart lighting» is being installed, which will save up to $65 \%$ of energy resources.

The next stage in creating a comfortable urban environment will be the Digital Twin, a platform for automated energy management in social institutions. Sensors installed on utility meters will accumulate a large amount of data over a long period of time and transfer them to a system that allows you to predict energy consumption and save up to $50 \%$ of the budget.

To create a comfortable urban environment, areas are created with «Smart doorphones» equipped with the SOS button, video calling and remote access functions through the smartphone application.

As part of the «Smart City» project, the «Active Citizen» digital system is being introduced. The Active Citizen system allows residents to report urban problems online, offer their solutions and receive answers from representatives of government and public services. An active citizen (applicant) creates a message and sends it to a moderator (administrator of a forum, chat or social network on the Internet). The moderator records the applicant's message, determines the executor and sends the applicant's message to the executor. The performer reacts to the message from the active citizen, creates a response and sends it to the moderator, who attaches the response to the applicant's message. The moderator sends a response to the applicant, and publishes the applicant's message and the artist's response on the forum, chat or social network on the Internet.

Currently, an effective program of solid municipal waste management is being implemented in the cities of the country, in which responsibility for the organization of waste management has been transferred from the municipal level to the regional level. In accordance with the environmental policy for working with municipal solid waste, recycling waste complexes are created.
Containers for separate collection of waste paper are installed in cities; plasticity; batteries, thermometers and energy-saving lamps. The introduction of a system of separate collection (accumulation), sorting and processing of municipal solid waste will: reduce the number of waste placed in landfills and landfills; ensure waste recycling; safe disposal of waste.

\section{DISCUSSION}

Having analyzed the information on the introduction of advanced promising technologies and practices, the implementation of the «Smart City» project in the cities of the country concluded that the introduction of the dispatching system for metering devices, the «Digital Twin» platform, «smart intercom phones», the «Active Citizen» digital platform, and the modern solid waste management system are positive for creating a comfortable urban environment, but insufficient.

It is proposed to use an automated system for organizing the removal of solid household waste, which includes:

1) protected ultrasonic sensor of the level of solid household waste in the container;

2) software for monitoring and for operational management of the solid waste disposal process.

The automated system for organizing the removal of solid household waste has the function of dynamically building optimal routes, accounting for the number of containers for garbage by type of waste (for separate waste collection), a smart prompt notification function, and a built-in system for generating a route sheet for drivers.

The principle of operation of the automated system for organizing the removal of solid household waste is as follows:

the operator monitors the level of filling of containers of solid household waste on the desktop of the application, selects containers filled above the specified percentage and creates a route sheet for the removal of solid household waste;

the driver receives a route list in the application on a mobile device or tablet with navigation and an optimal route that takes into account road traffic;

as containers of solid household waste are emptied, the driver marks them in the annex and leaves notes, if necessary (for example, damage to the container);

the operator sees marked containers with solid household waste and notes, has access to statistics and data that can be analyzed and created a report.

The ultrasonic sensor is installed in a container for solid household waste, and track how much garbage it has. Real-time data will be transmitted to utilities 
connected to a special information system. On the online map it will be possible to track the location of the container, the degree of its filling. The automated system for organizing the removal of solid household waste will promptly notify public utilities if vandals try to overturn a container with garbage or if the amount of garbage in the container exceeds the volume of the container, or the garbage will catch fire. The program of the automated system for organizing the removal of solid household waste allows you to analyze the speed of filling containers with garbage, which increases the accuracy of determining the required number of containers for separate collection of garbage in the city.

The COVID-19 pandemic has impacted the housing and utilities sector. Enterprises in the field of housing and communal services necessarily provide services for the daily treatment of the entrances of apartment buildings with disinfectants. The pandemic caused by COVID-19 has actualized digitalization issues in almost all spheres of life, and the housing and communal services system is no exception. The requirement of time was the automation of the dispatcher's workplace. Benefits of an automated dispatcher workstation:

1) registration of appeals of residents;

2) formation of applications for performance of works;

3) control of the life cycle of the requisition and work execution;

4) approval of works on the requisition (execution of work order, inclusion of works in the maintenance plan, suspension of works);

5) automatic generation of work order;

6) appointment of the contractor;

7) adding a work list to execute the requisition (from the handbook).

8) document scanning;

9) attach an electronic document to a work order

10) recording of sensor disconnections;

11) formation of reports on the implementation of applications of residents.

To create a comfortable urban environment, it is necessary to continue research on the functioning of the housing and communal services sector, the possibilities of introducing promising technologies and practices, and as a result, the formation of a closed-cycle economy.

\section{CONCLUSIONS}

Promising technologies and practices for creating a comfortable urban environment in the city are peopleoriented, and allow:

- to make transparent and modern the organization of labor in the field of housing and communal services;

- $\quad$ reduce the number of complaints of residents about housing and communal services;

- improve the quality of housing and communal services;

- $\quad$ quickly address problems in the urban economy;

- improve the public and environmental safety of the city;

- to release additional funds for the development of the housing and communal services sector by optimizing the dispatch services of the city.

Promising technologies and practices in the field of housing and communal services are aimed not only at creating a comfortable urban environment, but also at the economical and efficient use of the city's life support resources, that is, increasing resource conservation, and, as a consequence, at the formation of a circular economy. The Smart City project is being improved, developed and replenished with new technologies and practices in the field of housing and communal services.

\section{REFERENCES}

[1] E.V. Nikitinsk, The concept of OF THE HOUSING AND COMMUNAL SERVICES in the context of Russian legislation. In: Bulletin of Nizhny Novgorod University named after N.I. Lobachevsky, 2 (2018) pp. 162-165.

[2] Ben Lyons, Edward O’Dwyer, Nilay Shah, Energy, 197 (2020) 117178.

[3] Alexandr Zamiralov, Maria Khodorchenko, Denis Nasonov. In: Procedia Computer Science, 178 (2020) pp. 213-223.

[4] Yulia Kolyhaeva, Procedia - Social and Behavioral Sciences, 166 (2015) pp. 557-561.

[5] E. L. Nikolaeva, V. S. Kazeykin Artem, V. Sedov. Procedia Engineering Procedia Engineering, 91 (2014) pp. 390-393.

[6] Arkadiy Larionov, Yulia Larionova, Ludmila Selivanova, Procedia Engineering, 165 (2016) pp. 1229-1232.

[7] A. N. Afanasyeva, A. A. Guseinova, Procedia Engineering, 150 (2016) pp. 1941-1947.

[8] Lisa W. Gao, Daniel C. W. Ho, Habitat International, 57 (2016) pp. 233-241. 
[9] A. Synnefa, K. Vasilakopoulou, M. Santamouris, Energy and Buildings, 154 (2017) pp. 55-71.

[10] Edward O’Dwyer, Indranil Pan, Nilay Shah, Sustainable Cities and Society, 62 (2020) 102412.

[11] Julio Cesar Ferro De Guimarães, Eliana Andréa Severo, Fernanda Tasso Salmoria, Journal of Cleaner Production, 253 (2020) 119926.

[12] Marta Pappalardo, Gilles Debizet, Global Transitions, 2 (2020) pp. 221-229.

[13] Janaina Macke, João Alberto Rubim Sarate, Suane de Atayde Moschen, Journal of Cleaner Production, 239 (2019) 118103.

[14] Daniel A. Vallero, Fraser McLeod, Tom Cherrett, Waste (Second Edition), pp. 67-89 (2019).

[15] Cecilia Tortajada, Francisco González-Gómez, Joost Buurman, Sustainable Cities and Society, 45 (2018) pp. 649-656.

[16] Thomas Bjørner, Cities, 114 (2021) 103187.

[17] Xiaoyong Xiao, Chao Xie, Environmental Technology \& Innovation, 21 (2021) 101381.

[18] Mary Thornbush, Oleg Golubchikov, Environmental Development, 100626 (2021). 